\title{
SuperaçÃo de DormênCia de Sementes de Ceratophyllum demersum ${ }^{1}$
}

\author{
Dormancy Break of Ceratophyllum demersum Seeds
}

\begin{abstract}
COSTA, N.V. ${ }^{2}$, MARTINS, D. ${ }^{3}$, MARTINS, C.C. ${ }^{3}$, MARCHI, S.R..$^{2}$ e DOMINGOS, V.D. ${ }^{2}$
RESUMO - Dentre as várias plantas daninhas aquáticas imersas que proliferam nos reservatórios de usinas hidrelétricas, destaca-se em importância Ceratophyllum demersum, devido à sua grande capacidade de reprodução e produção de biomassa. Contudo, apesar de problemática, estudos relacionados com o mecanismo de propagação e persistência dessa espécie em ambiente aquático são bastante escassos no Brasil. Dessa forma, o objetivo deste estudo foi avaliar diferentes métodos de superação de dormência em sementes desta planta daninha aquática coletadas na Lagoa Vírgula, localizada no rio Tietê-SP. As sementes coletadas foram divididas em dois lotes, sendo um constituído por sementes acondicionadas em um recipiente contendo água destilada e o outro por sementes acondicionadas em sacos de papel em condições de câmara fria $\left(16,8^{\circ} \mathrm{C}\right)$. Após 650 dias da coleta das sementes, foram realizados os testes de superação de dormência, utilizando os seguintes tratamentos: escarificação manual; imersão em ácido sulfúrico concentrado $(98 \%)$ por $5,15,25$ e 35 minutos; imersão em água quente $\left(98^{\circ} \mathrm{C}\right)$; e testemunha $\mathrm{A}$, constituída pelo lote de sementes acondicionadas em um recipiente contendo água destilada, e uma testemunha B, constituída pelo lote de sementes acondicionadas em saco de papel. Os resultados demonstraram que a espécie $C$. demersum produz sementes férteis e podem permanecer viáveis no sedimento por vários anos após a fecundação. A escarificação das sementes foi o método mais eficaz na superação da dormência, sendo significativamente superior aos demais tratamentos e apresentando $65,0 \%$ de germinação aos 79 DAT. Ficou evidente a necessidade de realização de mais estudos para determinação de uma metodologia mais adequada à avaliação de dormência em sementes de C. demersum.
\end{abstract}

Palavras-chave: planta aquática, planta daninha, germinação, Ceratophyllaceae.

ABSTRACT - Ceratophyllum demersum is prominent among the several immersed aquatic weeds that proliferate in the reservoirs of hydroelectric power plants due to its great reproduction capacity and biomass production. Despite this problem, studies related to the propagation mechanism and persistence of that species in aquatic ecosystems are quite scarce in Brazil. Thus, the objective of this study was to evaluate different methods of seeds dormancy break of the aquatic weed C. demersum collected at Virgula Pond in Tiete River-SP Brazil. The collected seeds were grouped into two lots, one constituted by seeds in a container with distilled water and the other by seeds in paper bags under cold camera conditions $\left(16.8^{\circ} \mathrm{C}\right)$. Tests of dormancy break were accomplished 650 days after seed collection using the following treatments: I) Scarification, II) Immersion in concentrated sulfuric acid (98\%) for 5, 15, 25 and 35 minutes, III) Immersion in hot water $\left(98^{\circ} \mathrm{C}\right)$ and IV) Control A (seeds in a container with distilled water) and Control B (seeds in paper bags). The results showed that the species $\mathbf{C}$. demersum produces fertile seeds which can remain viable in the sediment for several years after fecundity. Seed scarification was the most effective method for dormancy break, significantly outdoing the other treatments and providing $65.0 \%$ of germination at 79 DAT. Further studies are needed to determine an appropriate methodology for seed dormancy break evaluation of C. demersum.

Key words: aquatic plant, weed, germination, Ceratophyllaceae.

1 Recebido para publicação em 20.12.2004 e na forma revisada em 23.2.2005.

2 Eng.-Agr., discente de Pós-graduação, Dep. de Produção Vegetal-Agricultura, FCA/UNESP < neumarcio@ fca.unesp.br>. ${ }^{3}$ Prof. Dr., Dep. de Produção Vegetal-Agricultura, FCA/UNESP, Caixa Postal 237, 18603-970 Botucatu-SP. 


\section{INTRODUÇÃO}

Dentre as várias espécies imersas que proliferam nos reservatórios das usinas hidrelétricas do Estado de São Paulo, destacam-se em importância duas espécies pertencentes à família Hydrocharitaceae: Egeria densa e Egeria najas. Contudo, nos últimos levantamentos florísticos realizados nos seis reservatórios operados pela Companhia Energética de São Paulo-CESP (Três Irmãos, Jupiá, Ilha Solteira, Porto Primavera, Paraibuna e Jaguari), a espécie Ceratophyllum demersum vem se destacando entre as 29 espécies de plantas daninhas aquáticas identificadas (Tanaka et al., 2002). Estas espécies aquáticas proporcionam sérios problemas em reservatórios de hidrelétricas e em lagos ou represas de pequeno porte, devido à sua grande capacidade de reprodução e produção de biomassa.

C. demersum é uma espécie herbácea pertencente à família Ceratophyllaceae, perene, desenvolve-se imersa ou flutuando, desprovida de raiz, porém possui folhas modificadas, que têm função de rizomas e podem servir como âncoras e para a absorção de nutriente. É uma espécie monóica, com flores que se desenvolvem totalmente imersas na água, e o processo de polinização somente ocorre em locais de água parada (Holm et al., 1977), ao contrário das espécies E. densa e $E$. najas, que são plantas dióicas e as flores unissexuais são expostas a cerca de $2 \mathrm{~cm}$ acima do nível da água; contudo, essas espécies multiplicam-se principalmente por fragmentação do caule, sendo a reprodução por sementes muito rara (Christopher \& Urmi-König, 1984; Bowmer et al., 1995; Kissmann \& Groth, 1997).

Ikeda \& Itoh (2001) afirmam que a dispersão de sementes pela água é uma característica de adaptação das plantas aquáticas para aumentar a habilidade de colonização de novas áreas. Existem na literatura, poucos estudos referentes à propagação da espécie C. demersum por meio de sementes.

C. demersum possui sementes com tegumento bastante rígido e impermeável, que apresentam dormência e podem permanecer viáveis no banco de sementes do ambiente por período indeterminado. A dormência em sementes é causada por diferentes mecanismos, que variam de acordo com a espécie; a utilização de métodos eficazes de superação da dormência pode promover uma germinação rápida e uniforme das sementes, sendo útil na avaliação da qualidade fisiológica, e contribuir com estudos referentes à biologia e ao controle da espécie, bem como com a dinâmica do banco de sementes.

Dentre os métodos de superação de dormência de sementes duras, pode-se citar a utilização de escarificação mecânica com lixa ou química em ácido sulfúrico ou clorídrico, a imersão em água quente e a incisão com lâmina ou estilete (Toledo \& Marco Filho, 1977; Brasil, 1992).

Apesar dos problemas causados por plantas daninhas aquáticas, principalmente em usinas hidrelétricas, estudos relacionados com o mecanismo de propagação e persistência dessas espécies no ambiente aquático são bastante escassos no Brasil. Dessa forma, o objetivo deste estudo foi avaliar diferentes métodos de superação de dormência em sementes da planta daninha aquática $C$. demersum coletadas na Lagoa Vírgula, localizada no rio Tietê-SP.

\section{MATERIAL E MÉTODOS}

O experimento foi conduzido no Núcleo de Pesquisas Avançadas em Matologia (NUPAM) ligado ao Departamento da Produção Vegetal da UNESP/campus de Botucatu, e a coleta das sementes de $C$. demersum foi realizada em 13/12/2002 no reservatório formado pela Usina Hidrelétrica Engenheiro Souza Dias (Jupiá), na lagoa Vírgula, localizada no leito do rio Tietê. Para determinação da localização do ponto de coleta das sementes foi utilizado um aparelho de GPS (Garmin), obtendo-se as seguintes coordenadas: latitude de $20^{\circ} 40^{\prime} 47^{\prime \prime} \mathrm{S}$ e longitude de $51^{\circ} 21^{\prime} 09^{\prime \prime} \mathrm{W}$ (UTM: 0463243 7713212).

As sementes foram divididas em dois lotes, sendo um constituído por sementes acondicionadas num recipiente contendo água destilada e o outro por sementes acondicionadas em saco de papel. Os lotes foram armazenados em câmara fria a uma temperatura de $16,8{ }^{\circ} \mathrm{C}$, durante 650 dias. Após esse período de armazenamento, foram realizados os testes 
de superação de dormência, utilizando-se os seguintes tratamentos: escarificação: as sementes foram friccionadas 10 vezes em uma lixa $n^{\circ} 150$, na região oposta ao eixo embrionário, e imersa em água destilada durante todo o período de instalação do teste; ácido sulfúrico: as sementes foram submersas em ácido sulfúrico concentrado (98\%) por 5, 15, 25 e 35 minutos e, em seguida, lavadas em água corrente por 5 minutos, sendo posteriormente imersas em água destilada durante todo o período de instalação do teste; água quente: as sementes foram imersas em $200 \mathrm{~mL}$ de água destilada aquecida a uma temperatura de $98{ }^{\circ} \mathrm{C}$ e deixadas em repouso na mesma água, fora do aquecimento por 24 horas em temperatura ambiente, sendo posteriormente imersas em água destilada durante todo o período de instalação do teste; e testemunha: foram utilizadas sementes sem tratamento de quebra de dormência de cada lote, imersas em água destilada durante todo o período de instalação do teste, sendo uma testemunha A, constituída pelo lote de sementes acondicionadas em um recipiente com água destilada, e uma testemunha B, constituída pelo lote de sementes acondicionadas em saco de papel.

$\mathrm{O}$ teste de germinação foi realizado com 200 sementes por tratamento, em quatro repetições. Após a aplicação dos tratamentos, as sementes foram colocadas para germinar em béqueres com $50 \mathrm{~mL}$ de água destilada, os quais foram posteriormente acondicionados em germinadores sob regime alternado de temperatura e de luz, correspondendo a $30^{\circ} \mathrm{C}$ por 9 horas de luz e $20^{\circ} \mathrm{C}$ por 15 horas de escuro.

Foram consideradas germinadas as sementes que apresentavam estruturas germinativas com comprimento superior a $4 \mathrm{~mm}$. As avaliações foram feitas semanalmente, até 42 dias depois da aplicação dos tratamentos (DAT). Após esse período, as sementes dos tratamentos com ácido sulfúrico, água quente e a testemunha B foram escarificadas, friccionando-se as sementes 3,3 e 10 vezes, respectivamente, em uma lixa $\mathrm{n}^{\circ} 150$, na região oposta ao eixo embrionário, e imersas em água destilada durante todo o período de instalação do teste, sendo avaliadas até aos 79 DAT. Os parâmetros de avaliação foram: sementes germinadas, sementes mortas e sementes dormentes, bem como o Índice de Velocidade de Germinação (IVG), determinado conforme metodologia preconizada por Maguire (1962). Para determinação da dormência, as sementes foram cortadas longitudinalmente e uma das metades colocada em solução aquosa de 2, 3, 5 trifenil cloreto de tetrazólio $(0,1 \%)$ a $35^{\circ} \mathrm{C}$, por quatro horas, no escuro. Após descarte da solução e lavagem em água, as sementes foram identificadas como dormentes ou mortas.

O delineamento utilizado no experimento foi o inteiramente casualizado, e os resultados foram submetidos à análise de variância pelo teste "f", sendo as médias de porcentagem transformadas em arco seno $\sqrt{ } \mathrm{x} / 100$ e comparadas pelo teste " $t$ " $(p>0,05)$.

\section{RESULTADOS E DISCUSSÃO}

A escarificação das sementes de Ceratophyllum demersum foi eficaz no processo de superação da dormência, diferindo significativamente dos demais tratamentos (Tabela 1) aos 42 DAT. Nesse periodo, somente os tratamentos água quente, ácido sulfúrico (5') e escarificação apresentaram germinação, com valores na ordem de 1,0, 1,5 e 61,0\%, respectivamente.

Na Figura 1 (A e C) está apresentada a germinação de sementes de C. demersum após o efeito dos tratamentos de superação de dormência ácido sulfúrico (5') e escarificação, aos 28 DAT, enquanto na Figura 1B é apresentada a germinação sem o efeito de tratamento de superação de dormência, após 650 dias de armazenamento em câmara fria.

Pelo fato de os resultados de germinação apresentarem-se inexpressivos, possivelmente pelo comprometimento do embrião promovido pelos tratamentos térmicos com água quente e o químico com ácido sulfúrico, realizou-se aos 42 DAT a escarificação destes tratamentos, além da testemunha B, para verificação dos possiveis danos causados ao embrião da semente. Dessa forma, verificou-se que após a escarificação todos os tratamentos com ácido sulfúrico apresentaram germinação com valores entre 9 e 25\%, destacando os tratamentos ácido sulfúrico (5') e ácido sulfúrico (15'), com as maiores taxas de germinação, na ordem de 17,8 e 23,5\%, respectivamente, aos 79 DAT.

Planta Daninha, Viçosa-MG, v. 23, n. 2, p. 187-191, 2005 
Tabela 1 - Resultados da análise do teste de germinação e o Índice de Velocidade de Germinação (IVG) em sementes de Ceratophyllum demersum após 650 dias de armazenamento em câmara fria. Botucatu-SP, 2005

\begin{tabular}{|c|c|c|c|c|c|c|}
\hline \multirow{3}{*}{ Tratamento } & \multirow{2}{*}{\multicolumn{3}{|c|}{$\begin{array}{l}\text { Sementes Germinadas } \\
\text { Dias após o tratamento }\end{array}$}} & \multirow{3}{*}{$\begin{array}{l}\text { Sementes } \\
\text { dormentes }\end{array}$} & \multirow{3}{*}{$\begin{array}{c}\text { Sementes } \\
\text { mortas }\end{array}$} & \multirow{3}{*}{ IVG } \\
\hline & & & & & & \\
\hline & 42 & 79 & $42+79$ & & & \\
\hline 1. Testemunha $\mathrm{A}$ & $0,0 \mathrm{~b}$ & $0,0 \mathrm{~d}$ & $0,0 \mathrm{e}$ & $99,0 \mathrm{a}$ & $0,5 \mathrm{~d}$ & $0,0 \mathrm{c}$ \\
\hline 2. Testemunha B & $0,0 \mathrm{~b}^{1 /}$ & $53,0 \mathrm{a}$ & $53,0 \mathrm{~b}$ & $45,0 \mathrm{~d}$ & $1,5 \mathrm{~cd}$ & $0,43 \mathrm{~b}$ \\
\hline 3. Escarificação & $62,0 \mathrm{a}$ & $4,0 \mathrm{~cd}$ & $65,0 \mathrm{a}$ & $27,0 \mathrm{e}$ & $7,5 \mathrm{abc}$ & $1,47 \mathrm{a}$ \\
\hline 4. Ácido Sulfúrico (5') & $1,5 \mathrm{~b}^{1 /}$ & $17,8 \mathrm{~b}$ & $19,3 \mathrm{c}$ & $80,0 \mathrm{bc}$ & $1,0 \mathrm{~d}$ & $0,15 \mathrm{c}$ \\
\hline 5. Ácido Sulfúrico (15') & $0,0 \mathrm{~b}^{-1}$ & $23,5 \mathrm{~b}$ & $23,5 \mathrm{~cd}$ & $69,5 \mathrm{c}$ & $7,0 \mathrm{ab}$ & $0,19 \mathrm{c}$ \\
\hline 6. Ácido Sulfúrico (25') & $0,0 \mathrm{~b}^{\mathrm{1}}$ & $16,0 \mathrm{~b}$ & $16,0 \mathrm{~cd}$ & $81,5 \mathrm{bc}$ & $2,5 \mathrm{bcd}$ & $0,13 \mathrm{c}$ \\
\hline 7. Ácido Sulfúrico (35') & $0,0 \mathrm{~b}^{1 /}$ & $9,5 \mathrm{bc}$ & $9,5 \mathrm{~d}$ & $89,5 \mathrm{~b}$ & $1,0 \mathrm{~d}$ & $0,08 \mathrm{c}$ \\
\hline 8. Água Quente $\left(98^{\circ} \mathrm{C}\right)$ & $1,0 \mathrm{~b}^{1 /}$ & $0,0 \mathrm{~d}$ & $0,0 \mathrm{e}$ & $86,5 \mathrm{~b}$ & $12,5 \mathrm{a}$ & $0,0 \mathrm{c}$ \\
\hline CV (\%) & 54,1 & 41,4 & 29,3 & 10,8 & 66,5 & 52,8 \\
\hline
\end{tabular}

Dados de porcentagem foram transformados em arco seno $\sqrt{\mathrm{x}} / 100$.

Médias seguidas de mesma letra na coluna não diferem estatisticamente entre si pelo teste $t(p>0,05)$.

1/ escarificação dos tratamenos com ácido sulfúrico, água quente e a testemunha B.

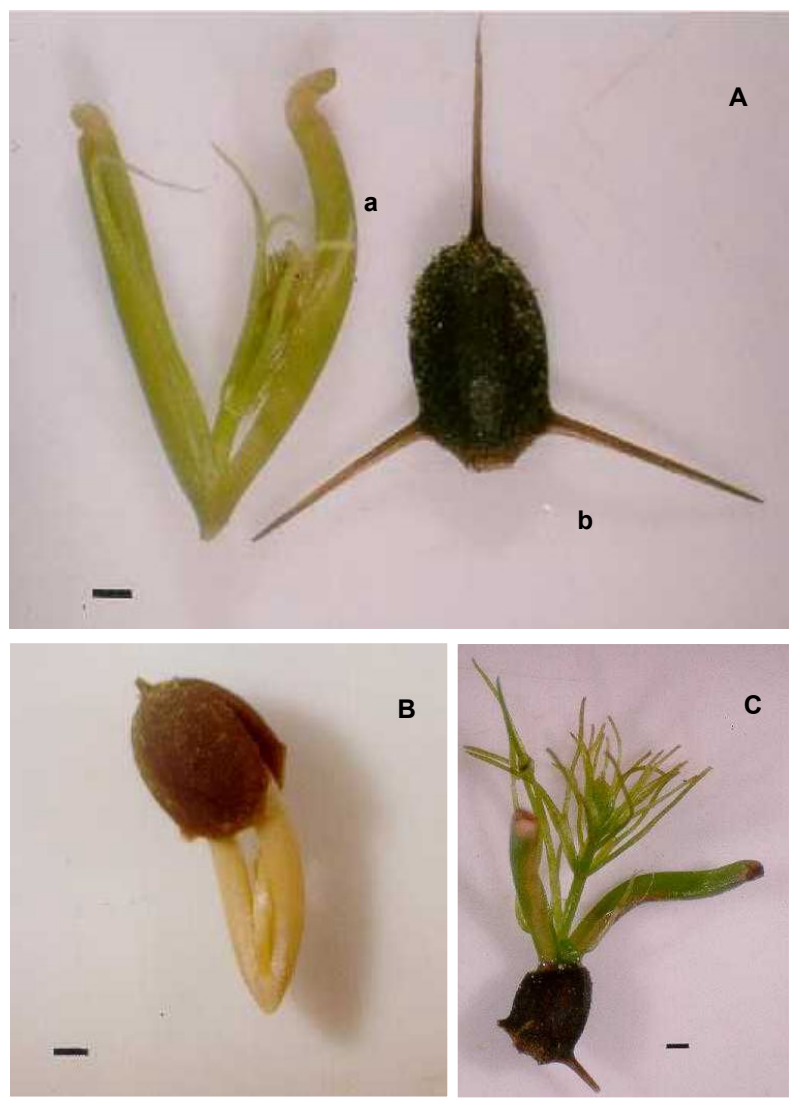

Figura 1 - Semente de Ceratophyllum demersum. A - Ácido Sulfúrico (5'), germinação aos 28 DAT. a = semente germinada. $\mathrm{b}=$ semente não-germinada. $\mathrm{B}$ - Germinação sem efeito de tratamento de superação de dormência, após 650 dias de armazenamento em câmara fria $\left(16,8^{\circ} \mathrm{C}\right) . \mathrm{C}-$ Escarificação manual, germinação aos 28 DAT. Barra $=1 \mathrm{~mm}$ $(\mathrm{A}, \mathrm{B}$ e $\mathrm{C})$.
A testemunha B apresentou a maior porcentagem de germinação - com valor em torno de 53,0\% aos 79 DAT -, evidenciando que as sementes de C. demersum podem permanecer viáveis no ambiente em locais não-alagados e por longo periodo de estiagem. Contudo, o tratamento com água quente obteve resultados insatisfatórios, com zero por cento de germinação, podendo-se inferir que altas temperaturas podem causar sérios danos ao embrião e prejudicar o processo de germinação.

Os tratamentos testemunha B e escarificação obtiveram os melhores resultados de IVG e de porcentagem de germinação em relação aos demais tratamentos, com valores na ordem de $0,43-53,0 \%$ e $1,47-65,0 \%$, respectivamente, aos 79 DAT.

Com relação à porcentagem de sementes mortas, os resultados foram variáveis, destacando-se o tratamento com água quente, com valor em torno de $12,5 \%$. A porcentagem de sementes dormentes foi maior no tratamento testemunha A, com 99,0\%. Entretanto, é importante ressaltar que a avaliação de sementes dormentes não apresentou resultados confiáveis devido à dificuldade da coloração do embrião pela solução de tetrazólio utilizada, sendo necessária a realização de mais estudos para determinação de uma metodologia mais adequada à avaliação da dormência em sementes de $C$. demersum. 
Por meio dos resultados obtidos, verificouse que a espécie $C$. demersum produz sementes férteis, corroborando os dados obtidos por Wyman \& Francko (1986), e que podem permanecer viáveis no sedimento por vários anos após a fecundação. Dessa maneira, essas características destacam-se como um importante mecanismo de adaptação, de dispersão e de colonização de novos ambientes aquáticos.

A escarificação foi o método mais eficiente na superação da dormência das sementes de C. demersum, demonstrando que o tegumento prejudica a passagem da água para o embrião, conferindo à semente uma dormência física (Baskin et al., 2000). Contudo, mais estudos devem ser realizados para compreender melhor o mecanismo de dormência das sementes dessa espécie, bem como a dinâmica ecofisiológica da germinação em ambiente aquático.

\section{LITERATURA CITADA}

BASKIN, J. M.; BASKIN, C. C.; LI, X. Taxonomy, anatomy and evolution of physical dormancy in seeds. Plant Species Biol., v. 15, p. 139-152, 2000.

BRASIL. Ministério da Agricultura e Reforma Agrária: Regras para análise de sementes. Brasília: SNDA/ DNDV/CLAV, 1992. 365 p.
BOWMER, K. H.; JACOBS, S. W. L.; SAINTY, G. R. Identification, biology and management of Elodea canadensis, Hidrocharitaceae. J. Aquat. Plant Manag., v. 33, p. 13-19, 1995.

CHRISTOPHER, D. K. C.; URMI-KÖNIG, K. A revision of the genus egeria (Hydrocharitaceae). Aquat. Bot., v. 19, p. 73-96, 1984.

HOLM, L. G. et al. The world's worst weeds, distribution and biology. Honolulu-U.S.: The East-West Center, 1977. 609 p.

IKEDA, H.; ITOH, K. Germination and dispersal of seeds from a threatened plant species Penthorum chinense. Ecol. Res., v. 16, p. 99-106, 2001.

KISSMANN, K. G.; GROTH, D. Plantas infestantes e nocivas. 2.ed. São Paulo: BASF, 1997. p. 290-293.

MAGUIRE, J. D. Speed of germination: aid in selection and evaluation for emergence and vigour. Crop Sci., v. 2, n. 2, p. 176-177, 1962.

TOLEDO, F. F. D.; FILHO, J. M. Manual de sementes, tecnologia de produção. São Paulo: Agronômica Ceres, 1977. 224 p.

TANAKA, R. H. et al. Ocorrência de plantas aquáticas nos reservatórios da Companhia Energética de São Paulo. Planta Daninha, v. 20, p. 101-111, 2002. (Edição especial)

WYMAN, C.; FRANCKO, D. A. Germination of Ceratophyllum demersum seeds in aseptic liquid culture. Proc. Oklahoma Acad. Sci., v. 66, p. 27-29, 1986. 